Predrag S. Mirčetić*

Filološki fakultet, Beograd
821.112.2.09 Брехт Б. ;

821.112.2.09 Шлегел Ф.

doi 10.18485/analiff.2015.27.2.8

\title{
BREHTOV VERFREMDUNGSEFFEKT VS. ROMANTIČARSKA IRONIJA F. ŠLEGELA
}

Cilj ovog rada je da ispita da li se ključan pojam Brehtove teorije epskog pozorišta, Verfremdungseffekt, može i treba čitati kao oblik romantičarske ironije. U radu se ukazuje na kontekstualne sličnosti između poetika Fridriha Šlegela i Bertolta Brehta i glavno zajedničko obeležje romantičarske ironije i Verfremdungseffekta - rušenje (književne i pozorišne) iluzije. Pozivajući se na različite primere iz celokupnog dramskog opusa B. Brehta, a pre svega komada Kavkavski krug kredom i Čovek je čovek, kao i savremene teorije metatetralnosti i intertekstualnosti na kraju rada se zaključuje da Brehtovo rušenje iluzije ima posve različitu funkciju od književne samosvesti. Funkcija Brehtove „romantičarske ironije“ jeste promena sveta.

Ključne reči: Bertolt Breht, Fridrih Šlegel, Verfremdungseffekt, romantičarska ironija, metateatralnost, intertekstualnost

Verfremdungseffekt ili V-effekt (Verfremdung - začuđenost, zapanjenost, čuđenje), ključan pojam teorije epskog pozorišta Bertolta Brehta (Berthold Brecht) kod nas se različito prevodio: efekat začudnosti ili V-efekat (Solar, 1982: 178; Brecht, 1966: 84, 113); potuđenje (Kostić, 1976: 26, 154); udaljavanje, otuđivanje, začudnost (Miočinović, 1975: 18-24, 429), oneobičavanje (Glumac, 1981: 17); efekat otuđenja (Ćirilov, 1964: 91) i efekat alijenacije, samootuđenje (Vujić, 1997: 164). Problem različitih i neadekvatnih prevoda postoji i u drugim jezicima, na primer engleskom: E-effekt, effect of estrangment, A-effect, alienation effect, distnacing effect (Styan, 1963: 188; Willett, 1967: 165). Budući da nijedan od prevoda "ne pokriva" sva značenja Verfremdungseffekta, i zbog opasnosti da bi asocijacije na pojmove kao što su oneobičavanje ruskih formalista i otuđenje Karla Marksa (Karl Marx) mogle u velikoj meri da suze značenja Verfremdungseffekta i budu uzrok njegovog pogrešnog shvatanja, na-

Studentski trg 3, 11000 Beograd; predragmircetic@gmail.com 
jboljim se čini koristiti originalni termin. Cilj ovog rada jeste da ispita $u$ kojoj meri se Brehtov Verfremdungseffekt može čitati kao nastavak čuvene romantičarske ironije Fridriha Šlegela.

Romantičarska "[i]ronija je permanentna parekbaza" (Šlegel, 1999: 125). Šlegel (Friedrich von Schlegel) je u ovom fragmentu na velika vrata uveo stanovište samorefleksije analogno umskom, transcedentnom stanovištu iz tada vladaćuje filozofije. Poetološka samosvest ("metafikcija") za koju se ponekad naivno veruje da je otkriće postmodernizma, ili njegovog oca Borhesa, zapravo je stara koliko i književnost ${ }^{1}$. Dovoljno je setiti se slepog pevača Demodoka i njegove forminge iz VIII pevanja Odiseje. Samorefleksija je nužan, ali nedovoljan uslov da se neko odredi kao postmodernista, jer bi u tom slučaju, ne samo Breht, već i Euripid i Homer postali postmodernisti. S druge strane, Velek (René Wellek) ipak nije u pravu kada tvrdi da F. Šlegel termin "romantizam" upotrebljava "sasvim nejasno i nastrano, kao neki element sve poezije, te tvrdi da sva poezija mora biti romantična" (Velek, 1966: 99-100) ${ }^{2}$. Kada Šlegel tvrdi da sva poezija mora biti romantična, mora se imati na umu šta za njega znači taj termin. Time on označava poziju koja je univerzalna, transcedentalna, autokritička, samorefleksivna poezija. Dakle, Šlegel je ipak donekle u pravu, možda ne u smislu da sva poezija mora biti samorefleksivna, već da sva, ili gotovo sva poezija to jeste (bila). Stojanović smatra da kada "slušamo o tome kako književnost ne samo da nešto prikazuje $\mathrm{i}$ da o nečemu govori, nego ona, u isti mah, mora da misli o sebi kao prikazivanju ili umetničkom govoru, i da tom mišljenju odmah da odgovarajući relevantni izraz u umetničkom delu" moramo da pomislimo pre svega na

1 Uporediti sa: "Samoposmatranje i prikaz onog pri tom opaženog, kao i referat o sopstvenom nastanku i o uslovima tog nastajanja, odavno postoje kao vid osobene spisateljske prakse" (Stojanović, 1999: 302, 313). Analiza Euripidovih Bahantkinja Zorana Milutinovića takođe upućuje na shvatanje da je poetološka samosvest vrlo stara, starija i od Sternovog Tristama Šendija, Fildingovog Tom Džonsa i Servantesovog Don Kihota. Prema Milutinoviću (1994: 32-33) Bahantkinje daju poetičko samorazumevnje tragičkog žanra kome pripadaju, objašnjavaju sopstvenu prirodu (koja nije istovetna poreklu samog žanra).

2 Šlegelova nejasna upotreba termina romantizam je po „nastranosti“ istovetna Brehtovoj upotrebi pojma realizam. I Fridrih Šlegel i Bertolt Breht termine koje je prisvojila istorija književnosti ne upotrebljavaju u književno-istorijskom nego "tipološkom" smislu. Breht doduše nije tvrdio da sva poezija mora biti realistična, iako je za realiste proglasio Servantesa, Svifta, Voltera, Šelija itd. 
Šlegela (Stojanović, 1999: 302).

Trebalo bi obratiti pažnju na poseban oblik refleksije - samorefleksiju ${ }^{3}$, odnosno, u kojoj meri se Verfremdungseffekt kao aktivna refleksija može shvatiti i kao samorefleksija, poetološka samosvest ("metateatralnost", "metadrama") i shodno tome povezati sa Šlegelovom romantičarskom ironijom. Potrebno je ograditi se od mogućeg pogrešnog razumevanja. Ne postoji podatak koji bi eksplicitno ukazivao na vezu Šlegelove romantičarske ironije i Brehtovog Verfremdungseffekta. Po svemu sudeći, "metateatralni" aspekt (Breht bi rekao artistički) kod Brehta svoj etimon ima pre svega $u$ istočnom pozorištu i načinu glume kineskog glumca Mej Lan-fanga (Brecht, 1966: 187-197). Međutim, ovo ne znači da se takve (vertikalne, a ne horizontalne) veze ne mogu naknadno uspostaviti, bez obzira na biografske, "spoljašnje" podatke, (bez obzira na intenciju autora, koja u "stara dobra formalistička"vremena nije smela biti predmet istraživanja, a u novijim postala formalno nepostojeća budući da je njen vlasnik - autor - mrtav).

Kontekstualna opravdanja za stav o Verfremdungseffektu kao permanentnoj parabazi mogu se naći ne samo u Brehtovim dramskim tekstovima, songovima i eshilovskom horu koji prekidaju i komentarišu radnju, već i drugim sličnostima koje se mogu uspostaviti između dva Nemca. Na primer: Šlegelov stav da fragment mora da bude "odvojen od sveta $\mathrm{i}$

3 Ostaje pitanje je da li je samorefleksija i u kom stepenu samo podvrsta refleksije, budući da refleksija ne podrazumeva onu podeljenost ili udvajanje (ljudskog) bića koja se javlja kod samorefleksije. "Spoznaj samog sebe" podrazumeva podvajanje ličnosti na bar dve osobe: A, ili onu koja spoznaje, i B, ili onu koja se spoznaje. Budući da je refleksija temporalan proces A može dospeti u položaj B, zbog čega će onda B postati C, čime se proces podvajanja može nastaviti ad infinitum. Problem podvajanja jasno se vidi u (Sokratovoj) rečenici: "Znam da ništa ne znam." Ova rečenica bi bez mogućnosti podvajanja, rascepa bila u najmanju ruku netačna - ako ništa ne znam onda ne mogu ni da znam da li (ne) znam. Međutim upravo zbog mogućnosti podvajanja onoga koji spoznaje, na onoga koji ništa ne zna i onoga koji zna da ne zna, na onoga koji poseduje (ne)znanje i onoga koji poseduje (ne)znanje o (ne)znanju, ili (ne)znanje (ne)znanja - ova rečenica može biti biti ne samo tačna, već i istinita. Pitanje da li je samorefleksija zaista samo oblik refleksije, njena podvrsta (pri čemu je samo/auto ili povratna rečca se differentia specifica), može se osvetliti i iz drugog ugla: da li je samoubistvo samo podvrsta ubistva, i da li bi, ako je to tako, onda samoubice zapravo trebalo slati u zatvor, bez obzira na uspešnost njihovog čina. 
dovršen sam u sebi, kao jež" i Brehtov zahtev da svaka scena u komadu bude izolovana celina koja ima sopstveno značenje; Šlegel nije smatrao važnim šta je u književnosti čije zbog "bratskog uzajamnog delovanja", a Breht je svoje "krađe", na primer Vijonovih balada za Operu za tri groša, objasnio svojom načelnom nemarnošću prema pitanjima duhovne svojine (Glumac, 1981: 28) ${ }^{4}$; svoje važne teorijske tekstove dali su u obliku dijaloga - Šlegelov Razgovor o poeziji i Brehtova Kupnja medi; Šlegelov stav "sva umetnost treba da postane nauka, a sva nauka umetnost" (Šlegel, 1999: 115) odgovara Brehtovom zahtevu za stvaranjem teatra naučnog razdoblja (Brecht, 1966: 44, 57); i na kraju, na prvi pogled najočiglednija (po nazivu), a zapravo najproblematičnija veza: Brehtova Velika umetnost (zajedničkog) življenja (Brecht, 1966: 112) neodoljivo asocira na Šlegeovu ironiju ljubavi (Šlegel, 1999: 115)

Poštenja radi, mora se naglasiti jedna veoma bitna razlika koja postoji između Fridriha Šlegela i Bertolta Brehta. Šlegelova ironija kao kritika umetnika usmerena prema samom sebi oznčava ono što je Šlegel označio kao samouništavanje. Nasuprot samouništavanju (kritici, razumskoj kontroli, racionalnom momentu u umetničkom stvaralaštvu) stoji samostvarenje kome odgovara iracionalan momenat, zanos ili nadahnuće. ${ }^{6}$ Šlegel je smatrao da se sa samoograničavanjem ne sme preterivati, da se mora "ostaviti prostora samostvaranju, izmišljanju i oduševljavanju” (Stojanović, 1999: 311) ${ }^{7}$. Za razliku od Šlegela, Breht ne poznaje momenat samostvaranja. On priznaje, iako mu to nije ugodno, da ne spada u onu vrstu pesnika koji kolutaju očima u ljupkom ludilu, vrstu neprirodnih bića koja sa božanskom sigurnoću spoznaju stvari koje drugi mogu spoznati samo sa veliko mukom i mnogo truda, te da se, i pored toga što postoji fantazija, on ne može dovoljno

4 Neki „teoretičari“ Brehtov elastičan odnos prema izvorima (kao i talentu i umetničkoj originalnosti) dovode u vezu sa njegovim marksističkim shvatanjem vlasništva i privatne svojine (Rastegorac, 1973: 28).

5 O Šlegelovom shvatanju ljubavi videti u: Stojanović, 1999: 306, 307, 309.

6 Prema Stojanoviću, podela na samouništavanje (kritika) i samostvaranje (genijalnost) ima dugu tradiciju od Pindara i Platona, koja se preko Horacija nastavlja sve do Bodlera. Reč je o kontrolisanoj inspiraciji, Šilerovom (naivnom) treznom pijanstvu umetnika i (sentimentalnom) zanosu s računom (Stojanović, 1999: 33-34).

7 Stojanović podseća na ono što je Alber Kami rekao u Naličja i lica: "Da bi se izgradilo, umetničko delo mora najpre da posegne za mračnim snagama duše. Mora, međutim da ih kanališe, da ih okruži branama, ali tako da se ipak može podići plima" (1999: 311). 
zagledati u sebe i u sebi pronaći sve uzroke koji su pronađeni kod ljudi. ${ }^{8}$ Breht se dakle odriče samostvaranja (iracionalno, fantazija), i prednost daje samouništavanju (razum, refleksija). Čini se da ova Šlegelova podela odgovara Brehtovim suprotnim pojmovima kao što su: osećanje i razum, učenje i zadovoljstvo (uživanje, zabava), umetnost i nauka.

Šlegel kaže da transcedentalna (romantičarska) poezija treba da bude kritička "da u svemu što predstavlja predstavi samu sebe, i svuda u istih mah bude poezija i poezija poezije" (Šlegel, 1999: 59). Postoji puno primera koji pokazuju da ova vrsta (poetološke) samosvesti postoji kod Brehta: teatar više ne krije da je teatar, ne tvrdi da je zbivanje na sceni zbivanje sâmo, već se u potpunosti vidi da je igra priređena; neki čovek "pred svima javno pokazuje nešto, pa i sâmo pokazivanje"; pokažite da pokazujete (Brecht, 1966: 80, 119, 129). Čini se da sam jezik prosto vapi da poveže Brehtovo pokazivanje pokazivanja sa Šlegelovom poezijom poezije. Iako Šlegel sam o tome ne govori, njegova poezija poezije zapravo je razaranje iluzije koju delo treba da stvori, odnosno, delo samim sobom naglašava da je u pitanju "puka" umetnička fikcija. Brehtov Verfremdungseffekt u svojoj osnovi, oneobičavanju, takođe je rušenje iluzije. Njegovo pokazivanje pokazivanja eksplicitno je povezano sa Verfremdungseffektom: bilo kao svojim izvorom, bilo kao njegovom posledicom, bilo da je ono samo Verfremdungseffekt. Na primer, (kineski) glumac postiže Verfremdungseffekt posmatranjem vlastitih pokreta, izražavanjem svoje svesti da ga gledaju, ili time što i sam čin pokazivanja čini umetničkim (Brecht, 1966: 117, 189-190, 232). Čini se da je veza Brehta sa romantičarskom ironijom obrazložena.

U prilog tome treba navesti i paroksizam ove "igre" rečima (znanje znanja, poezija poezije, pokazivanje pokazivanja). U pitanju je Brehtov iskaz o Verfremdungseffektu Verfremdungseffekta: "I ovim našim prikazom je sâm efekt začudnosti u izvijesnom smislu učinjen začudnim; pokušali smo da učinimo razumljivom učestalu, običnu operaciju, koja se svugda nalazi, time što smo je osvijetlili kao naročitu. Ali efekt nam je uspio samo kod onih koji su stvarno ('zaista') shvatili da se ovaj efekat 'ne' može postići bilo kakvim, 'nego' samo određenim načinom prikazivanja: on je samo 'zapravo' nešto uobičajeno” (Brecht, 1966: 122).

$8 \quad$ Uporediti sa: “Ali ljude ne upoznaje onaj koji samo sebe posmatra. Suviše toga skriva on od samog sebe. I nitko nije mudriji od samog sebe” (Brecht, 1966: 111). 
Međutim, i pored zajedničkog temelja, rušenja iluzije, Šlegelova romantičarska ironija i Brehtov Verfremdungseffekt se razlikuju u jednoj veoma bitnoj stvari: funkciji. Dok romantičarska ironija može da lebdi na krilima poetske refleksije u središtu između onog što predstavlja i onog što je predstavljeno, da vazda i iznova potencira tu refleksiju kao u kakvom beskrajnom redu ogledala (Stojanović, 1999: 33-34), Brehtov Verfremdungseffekt ima mnogo skromniji cilj - promenu sveta. Iako rušenjem iluzije pokazuje samosvest i otvara prostor za poetološka pitanja, funkcija Verfremdungseffekta se ipak sastoji samo u tome da uspostavi distancu sprečavanjem uživljavanja kod recipijenta i izazove kritčki stav kod gledoaca. Ključna razlika Verfremdungseffekta i romantičarske ironije može se bolje sagledati iz ugla metateatralnosti i metadrame. ${ }^{9}$

Mora se naglasiti da Breht metateatralnost upotrebljava na specifičan način, "samo" da bi porušio iluziju, da bi pokazao da nije u pitanju život već teatar, i time sprečio uživljavanje i izazvao kritički stav. Takođe je potrebno naglasiti da, ukoliko se prihvate klasična određenja meta-teatra/drame, Brehtovo pozorište jeste, ili se to bar pretpostavlja na osnovu njegovih teorijskih iskaza, uvek (permanentno) metateatralno, što se postiže na različite načine (npr. glumci se tokom predstave šminkaju na sceni, "ulaze" i "izlaze" iz lika, direktno se obraćaju publici, reflektori nisu skriveni već se vide, njihova maska je očigledna, kulise ne stvaraju iluziju da se na pozornici odigrava život, a ne drama itd.), dok samo neki njegovi tekstovi ulaze u metadramski krug.

Što se (metateatralnosti) predstava tiče, prema Vladimiru Jevtoviću Breht prilikom njihovog režiranja nije mnogo sledio teoriju u svom radu (1997: 201-202). Brehtove izjave: "Mi na scenu ne postavljamo nikakav efekat otuđenja već pozorišni komad," kao i da je glumici koja je isuviše dobro vladala teorijom ('bazom'), a bila slaba na sceni (u 'nadgradnji') rekao: "Ako ne počneš konačno da glumiš, šutnuću te u zadnjicu" (Grim, 1986: 153) podržavaju mišljenje Jevtovića, ili bar dokazuju lik Brehta zainteresovanog pre svega za praksu. Jevtović u daljoj analizi kaže da su

9 Termine metateatar i metadrama prvi je upotrebio Lajonel Ejbl (Lionel Abel) 1963. upotrebio i to u veoma širokom smislu. U kontekstu rečenice da je ceo svet pozornica, metadrama se pojavljuje kao antiforma jer predstavlja brisanje granica između umetnosti i života. Dž. L. Kaldervud (James L. Calderwood) metadramu shvata kao dramsko delo koje uspostavlja neku vrstu distinkcije prema sebi samom, osposobljava za autorefleksiju (Milutinović, 1999: 48). 
Brehtove predstave ipak bile normalne, ispunjene humorom, i pomalo naivne u prikazu likova iz dalekih krajeva (1997: 196-200, 201-204). Ako se zanemari pitanje na osnovu čega Jevtović zaključuje kakve su Brehtove predstave bile (da li zato što ih je gledao, ili što je gledao njihov snimak, a snimak predstave ipak nije što i predstava sama), treba obratiti pažnju na reč normalnost. Ukoliko se zanemari sporna implicitna premisa da postoje nenormalne predstave i pod pretpostavkom da je Jevtović pod 'normalnim' podrazumevao da se Brehtove predstave nisu razlikovale od predstava Stanislavskog, onda se dovodi u pitanje naša teza o Brehtovoj permanentnoj metateatralnosti. Međutim, kao dokaz naše tvrdnje možemo navesti osudu Brehtovih predstava koje je izneo Huga Klajn - prosečnom gledaocu je dodijalo mešanje glumca i lika, ulaženje i iskakanje iz uloge, pozorišna sredstva kojima Breht ostvaruje Verfremdungsefekt postala su sumnjiva, gluma se pretvorila u razgovor sa publikom o društvenim uslovima (Rastegorac, 1973: 20-22) ${ }^{10}$. Na osnovu fotografija Brehtovih predstava u knjizi The Theater of Bertolt Brecht (Willett, 1967), bar na osnovu dekora, takođe se može tvrditi da one nisu baš sasvim 'normalne' u smislu da ne uspostavljaju referencijalnu iluziju koju je Stanislavski želeo da postigne (da sve treba da bude istinito i prirodno kao u životu), odnosno da je Breht ipak primenjivao teoriju u praksi.

Kao metadramske oblike autorefleksivnosti Milutinović navodi komad u komadu, raspolućenost lika, poetološke iskaze i hermeneutički ključ (Milutnović, 1994: 8) ${ }^{11}$. Brehtova metadrama uglavnom ima oblik komada u komadu. Milutinović kaže da iako komad u komadu skreće pažnju na artificijelnost, teatralnost drame, on ne mora isključivo da razbija dramsku iluziju, npr. kod Pirandela ona se ni za jedan jedini trenutak ne narušava

10 Treba pomenuti da su Klajnove osude nastale zbog Brehtovog odbacivanja upravo onoga što Jevtović zove 'normalnim', zbog legitimnog, ali (bar u odnosu na Brehta) 'reakcionarnog' shvatanja lika i pozorišta: dramsku i pozorišnu umetnost karakteriše zbivanje, umetnost je slika životnih zbivanja, zbivanja u živim likovima, ujednom živom svetu, svetu koji ne trpi da se stvaraoci mešaju u njegovu dalju sudbinu itd.

11 Metateatralna raspolućenost lika znači da jedan deo ostaje u ulozi i svetu drame, a drugi istupa sa komenatrom pred publiku da je opomene da gleda umetničko delo, a ne život. Hermeneutički ključ je dramski segmet koji daje veštinu tumačenja koja bi se primenila na dramu kao celinu, odnosno, ako smisao segmenta odgovara pretpostavljenom smislu drame kao celine i obratno onda je taj segment ključ za razumevanje (Milutinović, 1994: 9, 10). 
(1994: 8). Kod Brehta, naprotiv njegova jedina funkcija jeste u rušenju iluzije, pokazivanju da nije reč o stvarnom životu već samo "vazdušastom ničem". Drugim rečima, ono po čemu se Brehtova metadrama razlikuje od većine drugih metadrama je u tome što kod njega poetološka refleksija nije tematsko i strukturno središte (Milutinović, 1994: 11). Smisao pozorišne družine u Snu letnje noći ili Pirandelovih šest lica jeste upravo u samopredstavljanju, za razliku od kolhoznika u Kavkaskom krugu kredom koji igraju predstave o Gruši i Azdaku da bi osvetlili ne problem pozorišta, već problem vlasništva. Međutim, postavlja se pitanje da li se bez obzira na nepoetološku intenciju Brehtova dva komada u komadu može izvući implicitna poetika. ${ }^{12}$

Dakle, da li umetnute priče daju ključ za tumačenje same drame, drame u celini. Prema Milutinoviću priča o Gruši, Nateli Abašvili i dečaku Mihailu jeste klasičan komad u komad koji treba razjasni sporni slučaj doline. U osnovi ove parabole (Brehtov termin) ili exempluma leži odnos analogije između dva elementa, odnosno da ono što je prihvaćeno i potvrđeno u jednom trebalo bi da važi i drugom slučaju (Milutinović, 1994: 119). Drugim rečima, pouka da dolina treba da pripadne onome ko će se bolje brinuti o njoj, data je preko stava da je 'prava' majka ona koja se bolje ili zaista brine o svom detetu. Međutim, čini se da se iz ove analogije može izvući i jedan pohvalni poetološki iskaz o samoj pozorišnoj/dramskoj umetnosti, ili bar njenoj upotrebnoj vrednosti. Na osnovu analogije da je odnos umetnutog komada prema okvirnom komadu koji za njega predstavlja stvarnost jednak odnosu drame kao celine prema stvarnom svetu može se zaključiti da drama kao celina tumači i razjašnjava, donosi spoznaju spornih slučajeva iz stvarnog sveta. Kao primer mogu se navesti i sve one scene u kojima tokom parnica sudi sudija Azdak. Njihov cilj je da pouče načinu zaključivanja koji se demonstrira, a koji potom treba primeniti na tumačenje drame u celini (Milutinović, 1994: 121) ${ }^{13}$.

Ukoliko bi prihvatili uže određenje metadrame, tj. da komad u komadu moraju da prikazuju samo glumci, kao npr. u "Mišolovci", onda bi

12 Imanentna poetika podrazumeva da strukturalni i tematski elementi ostaju u ravni dela, ali da imaju poetološku funkciju tj. poetički uređuju, koncipiraju, legitimišu i vrednuju umetničku praksu kojoj pripadaju (Milutinović, 1994: 6).

13 Važno je napomenuti da scene u kojoj se deca igraju priče o gubernatoru i Azdakova gluma kneza iako podsećaju na "uobičajenu postmodernističku igru kineskim kutijama, lavirintima i ogledalima" nemaju za cilj "beskonačno umnožavanje odraza" (Milutinović, 1994: 182). 
samo Kavkaski krug kredom ispunjavao taj uslov, pa i on samo delimično - seljaci voćarskog kolhoza su spremili predstavu pod vođstvom profesionalnog umetnika, pevača Arkadija Čeidzea. Ako metadramu shvatimo malo šire, ali ne i metaforičnije, odnosno da je ona prisutna uvek kada postoji neka vrsta izvođenja ili predstavljanja, kada lik glumi/igra/predstavlja drugi lik, onda brojne Brehtove drame (zbog suspenzije Verfremudngseffekta u smislu obnaživanja) jesu metadrame: prosjaci u Operi nisu 'pravi' jer glume da su prosjaci, Šaj-Tu u Dobrom čoveku iz Sečuana igra zlog strica Šen-te. Kostić, na primer, smatra da i $U$ džungli gradova postoji pozorište u pozorištu, jer Garga i Šlink - personae dramaties kroz boks mečeve igraju Remboa i Verlena - personae alterae (1976: 45). U ovom kontekstu posebno je zanimljiva drama Čovek je čovek u kojoj se glavni lik Gali Gej odriče svoje, da bi na sebe navukao drugu ličnost kao glumac kostim. Scena suđenja, iako je ne igraju profesionalni glumci kao u Hamletu, već pripadnici engleske kolonijalne vojske, dakle glumciamateri, klasičan je primer komada u komadu: zbog tobožnjeg prestupa (prevara zbog tobožnjeg slona), Gali je tobože osuđen na smrt i streljan ćorcima. Čitava scena suđenja je odigrana da bi Gali Gej bio premontiran u krvožednu vojničnu. Glavni junak je zapravo onaj idealan gledalac iz sistema glume Stanislavskog koji ne razlikuje stvarnost od fikcije. Iz ovoga bi se možda mogla izvući implicitna kritika pozorišta iluzionizma koje počiva na uživljavanju - kada pozorište uspe da ostvari totalnu iluziju života na daskama koje život znače, onda recipijent (u ovom slučaju Gali Gej) postaje čudovište. Predstava (halucinacija) uspela, Gali Gej "mrtav", rodio se Džipi, mašina koja će se od svojih tvoraca-saboraca najviše isticati po zverstvima.

Specifičnost metateatralnosti i metadrame kod Brehta, budući da zapravo predstavljaju jedan od oblika Verfremdungseffekta može se postaviti i iz ugla njima srodnog pojma: intertekstulanosti ${ }^{14}$. Sve ono što Kostić navodi kao postizanje Verfremdungseffekta stilom, zapravo je verbalni Verfremdungseffekt zasnovan na intertekstu: upotreba jezika luteranske Biblije i stihova Remboa i Verlena u Dobošima u noći, stihova klasične nemačke drame (Getea i Šilera) u $U$ džungli gradova i Svetoj Johani

14 Pojam intertekstualnost skovala je i prva upotrebila Julija Kristeva (Julia Kristeva) na osnovu lingvističkih radova Ferdinanda de Sosira (Ferdinand de Saussure) i Mihaila M. Bahtina (Михаил Михайлович Бахйин) (Graham, 2000: 8-60). 
Klaoničkoj, Kiplinga i njegove "Balade iz bivaka" u Čovek je čovek, Džon Gejove Prosjačke opere, Vijonovih balada, motivi iz opere Madam Baterflaj u Operi za tri groša stiha elizabetanske drame i direktna parodija Geteovog Fausta i Šeskpirovog Ričarda III u Zadrživom usponu Artura Uija - Šekspirovim jambom govori se o trovanju karfiolom, a gangsteri se služe njime dok pričaju o pljački i ubistvima (Kostić, 1976: 28, 37, $62,77,122,223)$. Intertekst se ne mora zasnivati samo na stilu već može biti i parodija dramskih postupaka. U Svetoj Johani Klaoničkoj Maulerovo pismo u klasičnim stihovima je parodija ekspozicije tragedije, razgovora glavnog junaka sa svojim poverenikom - Mauler više ne želi da se bavi prodajom mesa, jer srce mu se para kada gleda jadne životinje kako umiru, to je i suviše krvav posao; u istom komadu parodira se Šilerova scena prepoznavanja iz Device orleanske u kojoj Johana prepoznaje kralja Karla po nebeskom svetlu, a kod Brehta Maulera po krvavom licu (Kostić, 1976: $62,125,127)$.

Svi Brehtovi Gegenstück komadi, obrade tekstova drugih pisaca (Koriolan, Antigona, Don Žuan, Život Edvarda II engleskog, Mati,) ili obrade koje su prekoračile tu svoju probitnu nameru i postale sasvim novi komadi (japanski nō komad Taniku - Onaj koji govori da, onaj koji govor ne, Prosjačka opera Džon Geja - Opera za tri groša, Šeskpirova Mera za meru - Okrugloglavi i šiljoglavi, "Knjiga kraljeva" iz Starog zaveta i kineski tekst Krug kredom od Ci-Meing-Cua iz XIII veka - Kavkavski krug kredom) spadaju u intertekst.

Postavlja se pitanje zašto se ove intertekstualne parodije moraju shvatiti kao jedan od oblika Verfremdungseffeka. Govoreći o odnosu umetnosti i nauke Breht kaže da "Bilo koliko znanja da postoji u nekoj poeziji, ono mora biti potpuno preobraženo u poeziju. Njegovo prerađivanje zadovoljava upravo onaj užitak koji priprema pjesništvo" (Brecht, 1966: 74) Drugim rečima, ovo mistično preobražavanje svega što postoji u poeziji u poeziju moglo bi se primeniti i na Verfremdungseffekt, odnosno, da sve što se nađe u vidokrugu njegove suspenzije postaje Verfremdungseffekt, te da tri aspekta Verfremdungseffekta (oneobičavanje, dijalektika, angažman) diktiraju Brehtovu specifičnu upotrebu interteksta. Za razliku od 'pravog' interteksta Brehtov intertekst se po pravilu može čitati, razumeti i tumačiti i bez temeljnog poznavanja tekstova drugih pisaca koje je "ukrao", parodirao itd. zato što smisao Brehtovog interteksta i nije evociranje drugih tekstova, niti se u njemu iscrpljuje niti od njega zavisi. Kada Simon iz Kru- 
ga kredom kaže: "Vrijeme je lijepo, rekao je ribar crvu. - Hoćemo li loviti ribu?" (Brecht, 186 :122) intencija nije da se uspostavi veza sa iskazom Majke: "Pođimo na pecanje, reče ribar crvu" (Brecht, 164 :122). Šta više došlo bi do pogrešnog tumačenja oba iskaza, i to na štetu njihovih "denotacija”, budući da se Simonov crv odnosi na pravdu (i vlasništvu), a Majčin na rat. Kada Breht kaže da njegovi glumci treba da tekst izgovaraju kao da citiraju, a ne improvizuju, to znači da treba da pokažu artistički moment, da je predstava spremljena, a ne da se događa "sada i ovde" (Brecht, 1866: 120). 'Citiranje' kao način glume i (auto)citat kao intertekst imaju dakle isti cilj: rušenje iluzije, sprečavanje uživljavanja, uspostavljanje distance, itd. ${ }^{15}$

Dakle, Brehtova transtekstualnost ${ }^{16}$ : metatekst (komad u komadu), peritekst ('epski pripovedač') i intertekst (citati) nije 'prava' ili 'puna' transtekstualnost budući da je u pitanju Vefremdungseffekt. Brehtova transtekstualnost je samo "fenomenska", odnosno, ona kao takva "ontološki" zaista postoji u njegovim komadima ali se sa 'pravom' transtekstualnošću samo donekle poklapa. Dok 'prava' transtekstualnost ostaje 'zatvorena' u sebi, ne odlazi dalje od teksta ili svog odnosa prema tekstu, Breht pravi iskorak iz nje. On angažovano prelazi "rampu" i izlazi izvan korica da bi putem ,romantičarske ironije“ delatno menjao svet.

\section{Literatura:}

Brecht, B. (1966). Dijalektika u teatru. (D. Suvin, prev.) Beograd: Nolit. Brecht, B. (1986). Kavkaski krug kredom. (N. Milovac, prev.). Zagreb: August Cesarec.

Breht, B. (1964). Majka Hrabrost i njena deca. (T. Šenk i J. Ćirilov, prev.) Beograd: Rad.

Ćirilov, J. (1964). Bertolt Breht i epsko pozorište. U B. Breht, Majka Hrabrost i njena deca (T. Šenk i J. Ćirilov, prev.) (pp. 87-92). Beograd: Rad.

Glumac, S. (1981). Četiri Brehtova komada. U B. Breht, Četiri komada (S. Glumac, prev.) (pp. 7-36). Beograd: Nolit.

15 Intertekst su, prema Milutinoviću, oblici kao što su citat, aluzija, montaža ili parodija (Milutinović, 1994: 11).

16 Pojam transtekstulanost uzimam u onom smislu u kojem ga koristi Ženet u svom radu "Uvod u arhitekst" (Ženet, 1985:189). 
Grim, R. (1986). Katolički Anštajn: Brehtova teorija drame i pozorišta. Književna kritika, 2-3, 150-157.

Graham, A. (2000). Intertextuality. London - New York: Routlegde.

Jevtović, V. (1997). Pozorišna publika: svedok ili saučesnik. Zbornik radova Fakulteta dramskih umetnosti, 1, 196-211.

Kostić, P. (1976). Drama i pozorište Bertolta Brehta. Sarajevo: Svjetlost.

Milutinović, Z. (1994). Metateatralnost (imanentna poetika u drami XX veka). Beograd: Studentski izdavački centar.

Miočinović, M. (prir.) (1975). Rađanje moderne književnosti: Drama. Beograd: Nolit.

Rastegorac, I. (prir.). (1973). Univerzalni Breht. Beograd: Centar za kulturu i umetnost.

Solar, M. (1982). Savremena svijetska književnost. Zagreb: Školska knjiga. Stojanović, D. (1999). Mislilac romantizma Fridrih Šlegel. U Šlegel, F., Ironija ljubavi (pp. 301-313). Beograd: Zepter Book World.

Styan, J. L. (1963). The Elements of Drama. Cambridge: Cambridge University Press.

Šlegel, F. (1999). Ironija ljubavi. (D. Stojanović, prev.). Beograd: Zepter Book World.

Velek, R. (1966). Pojam romantizma u književnoj istoriji. U R. Velek, Kritički pojmovi. (A. I. Spasić i S. Đorđević, prev.) (pp. 96-135). Beograd: „Vuk Karadžić“".

Vujić, I. (1997). Tekst i podtekst u velikim rediteljskim sistemima XX veka (Stanislavski,

Breht, Grotovski, Šekner, ka podtekstu). Zbornik radova Fakulteta dramskih umetnosti, 1, 158-168.

Willett, J. (1967). The Theater of Bertolt Brecht. London: University Paper Backs.

Ženet, Ž. (1985). Figure. (M. Miočinović, prev.) Beograd: GRO "Kultura". 
Predrag S. Mirčetić

\section{Summary}

\section{BRECHT'S VERFREMDUNGSEFFEKT}

vS. SCHLEGEL'S ROMANTIC IRONY

The aim of this paper is to examine whether the key concept of Brecht's theory of epic theater, Verfremdungseffekte, could be read as a form of romantic irony. The paper points to the contextual similarity between the poetics of Frederick Schlegel and Berthold Brecht and the most important feature of romantic irony and Verfremdungseffekte - breaking of (literary and theatrical) illusion. Referring to the various examples from the entire dramatic oeuvre of B. Brecht, primarily pieces Caucasian Chalk Circle and Man Equals Man, and the modern theory of metatheatre and intertextuality, it is concluded that Brecht's breaking of illusion has a completely different function than literary self-consciousness. The function of Brecht's ,,romantic irony“ is to change the world.

Key words: Berthold Brecht, Friedrich Schlegel, Verfremdungseffekte, romantic irony, metatheatre, intertextuality 